\title{
ASSESSMENT OF MENSTRUAL HEALTH AND ANALGESICS USAGE IN YOUNG AGE WOMEN
}

\author{
ALMOHAMMADI AMEEN, JUNAID SUHAIL, SHORBATLI LOUJAIN, AL-SOMALI AMAL
}

\author{
Associate Professor of Clinical Pharmacy Saudi Arabia
}

Email: amalmohammadi@kau.edu.sa

Received: 19 Nov 2019, Revised and Accepted: 20 Dec 2019

\section{ABSTRACT}

Objective: The study focuses on assessing the incidence of menstrual irregularity among young women and the factors for a disturbance with the rationale to assess the use of analgesic drugs during Premenstrual Syndrome (PMS).

Methods: A cross-sectional study was used. A total of 2500 randomly selected young female between the age of 11 and 30 y completed the study questionnaire to assess lifestyle pattern, variations in menstrual pattern, perceived stress, and to capture information about their menstrual cycle and related problems. In addition, the questionnaire assessed the use of analgesics for PMS.

Results: 2481 participants completed the questionnaire. The mean age of participants' menarche was $12.85 \pm 1.432 \mathrm{y}$. The prevalence of menstrual irregularities was $25.0 \%(n=621)$ and about $8.5 \%(n=211)$ of respondents had severe pain that was not relieved by the use of analgesics. On the other hand, $50.9 \%(\mathrm{n}=1262)$ reported severe pain that was relieved by analgesics. A total of $1279(51.6 \%)$ of participants in this study used 0ver The Counter (OTC) analgesics to relieve PMS.

Conclusion: Dysmenorrhea is the most common complaint among young females in Saudi Arabia. Low Body Mass Index (BMI), sedentary lifestyle, stress and early age of menarche are the most important factors associated with menstrual irregularities. Proper education programs and awareness among young girls about their menstrual health, and the provision of guidance in choosing effective analgesics and treatment options for dysmenorrhea are highly recommended.

Keywords: Premenstrual syndrome, Dysmenorrhea, Menstrual irregularity, Menarche, OTC analgesics, Menstrual pain

(C) 2020 The Authors. Published by Innovare Academic Sciences Pvt Ltd. This is an open-access article under the CC BY license (http://creativecommons.org/licenses/by/4.0/) DOI: http://dx.doi.org/10.22159/ijpps.2020v12i2.35099. Journal homepage: https://innovareacademics.in/journals/index.php/ijpps

\section{INTRODUCTION}

Adolescence is not just a transitional phase for a girl but a biologica indicator of physical and spiritual development. This phase is very significant for young females due to the onset of menstruation and progression to womanhood [1]. Health care professionals play a vital role in the support and progress of women in any society. In addition both the physiological and psychological effects determine the women's wellbeing [2]. Menstruation is a biological process characterized as a short or long, predictable event process of eliminating unused, ruminants from the lining of the uterus until pregnancy. The menstrual cycle may vary from month to month and over the years, or may remain the same. The menstrual phenomenon may be normal for one woman but may not be for another [3, 4]. A female's menarche may vary according to region or population and can even be influenced by geography, nutritional status, racial or environmental changes or individual factors [5-7]. Menses onset is on average $28 \pm 3 \mathrm{~d}$ in $80 \%$ of women, ranging between 18-41 d. The absence of menses could result from pregnancy, lactation and menopause. These causes should be ruled out as a cause of abnormalities [8].

In order to educate and support young girls at menarche, a policy booklet was released by UNESCO (2014) as guidance to support administrators and teachers in educational institutions [9]. To build up self-esteem and to engage young girls in discussions about menstruation, Procter and Gamble has launched communication programs across globe and even provided sanitary pads for developing countries [10]. Worldwide, many studies and research have individually reported that emotional and hormonal disturbance, stress and sedentary lifestyle serve as factors that affect a women's menstrual cycle. From the reproductive ages the most common menstrual issues are secondary amenorrhea, oligomenorrhea, dysmenorrhea and menorrhagia. Secondary amenorrhea has a prevalence of 1 to $3 \%$ in women. The incidence can differ from $3-4 \%$ and 5 to $50 \%$ in students and athletes, respectively [1115]. However, the girl's knowledge about the duration and variation within menstrual days is useful for the educational process and may facilitate the recognition of any unusual changes that can help in detailed clinical evaluation [16]

In the Kingdom of Saudi Arabia there is no evidence that shows how these factors affect the menstrual cycle of young women. Also, to date there is no data supporting the rationale of using analgesics during PMS. Therefore, this study aims to determine the average menarche age and incidence of menstrual irregularities among girl and young women and to assess the factors influencing PMS and the use of analgesic drugs to counter the pain during PMS.

\section{MATERIALS AND METHODS}

\section{Study design and setting}

The study consisted of independent cross-sectional analysis conducted randomly in a different area of Jeddah city and included three intermediate schools, four secondary schools, two universities and three shopping malls.

\section{Participants}

A self-administered questionnaire was distributed randomly to reach 2500 young females between the ages of 11 to $30 \mathrm{y}$ old. All participants were given the study's questionnaire which required $15 \pm 5$ min to complete. The questionnaire consisted of four parts in addition to a section on demographics. The first part was to assess the lifestyle patterns of the participants.

\section{Variables}

The second part recorded variations in bleeding patterns considering the menarche age, menses duration, total days of flow cycle, and blood loss. The severity of menstruation and analgesics use during PMS was also assessed. The third section assessed individual stress status using the Global Measure of Perceived Stress [17] after translation to Arabic. The last part assessed the level of 
information that the participants have about their menstrual cycle and related problems.

\section{Validation process of the study protocol}

The questionnaire was designed to be simple and easy to understand in order to extract the age of menarche, irregularities and use of anti-inflammatory drugs during PMS [18]. After the items were constructed and the four sections were completed, the questionnaire was sent to an expert panel consisting of gynecologists, clinical pharmacologists, pharmacists, medical residents and Arabic language teachers. The questionnaire and collected data were thoroughly validated [19]. The reliability of the questionnaire was pilot tested over a population size of 100 young girls from university in order to eliminate unclear or ambiguous questions [20].

\section{Statistical analysis}

All data were analyzed using SPSS PCTM software package. Descriptive statistics, T-tests, Mann-Whitney and Kruskal-Wills tests were instrumental in data analysis. Statistical significance of $\mathrm{P}<0.05$ was employed throughout the study.

\section{RESULTS}

\section{Participants, characteristics}

A total of 2500 females were invited and participated in the study, 2481 (98.24 \%) questionnaires were promptly completed and the obtained data were entered for statistical analysis. The majority up to $90.7 \%(n=2251)$ of participants were Saudi young women. The participants' average age ranged between 11 to 30 y $(19.83 \pm 3.05)$. Most of the participants $89.7 \%(\mathrm{n}=2226)$ were single and the others $81.5 \%(n=2021)$ were living with their parents. $95.3 \%(n=2364)$ of participants were students and worked for more than $6 \mathrm{~h} 65.0 \%$ $(n=1613)$. Only $3.1 \%(n=76)$ of participants had a confirmed chronic disease (table 1). Body mass index (BMI) showed that the majority about $71.6 \%$ ( $\mathrm{n}=1777)$ of participants had normal weight. Statistical analysis revealed that those with lower BMI had more menstrual irregularities than others $(\mathrm{P} \leq 0.001)$ (fig. 1$)$.

Table 1: Demographic characteristic of participants in the survey

\begin{tabular}{lll}
\hline Variable & Number of participants & Percentage (\%) \\
\hline Marital status & 2226 & \\
Single & 248 & 89.7 \\
Married & 7 & 10.0 \\
Divorced & 2021 & 0.2 \\
Living With & 187 & 81.5 \\
Both parents & 18 & 7.5 \\
One of the parents & 255 & 0.7 \\
Relatives & & 10.3 \\
Own Place & 2364 & 95.3 \\
Occupation & 116 & 4.7 \\
Student & & \\
Other & 118 & 4.8 \\
Working Hours & 747 & 30.1 \\
Less than 6 h & 1616 & 65.1 \\
6 h & & \\
More than 6h & 76 & 3.1 \\
Chronic Disease & 2405 & 96.9 \\
Yes & & \\
No & & \\
\hline
\end{tabular}

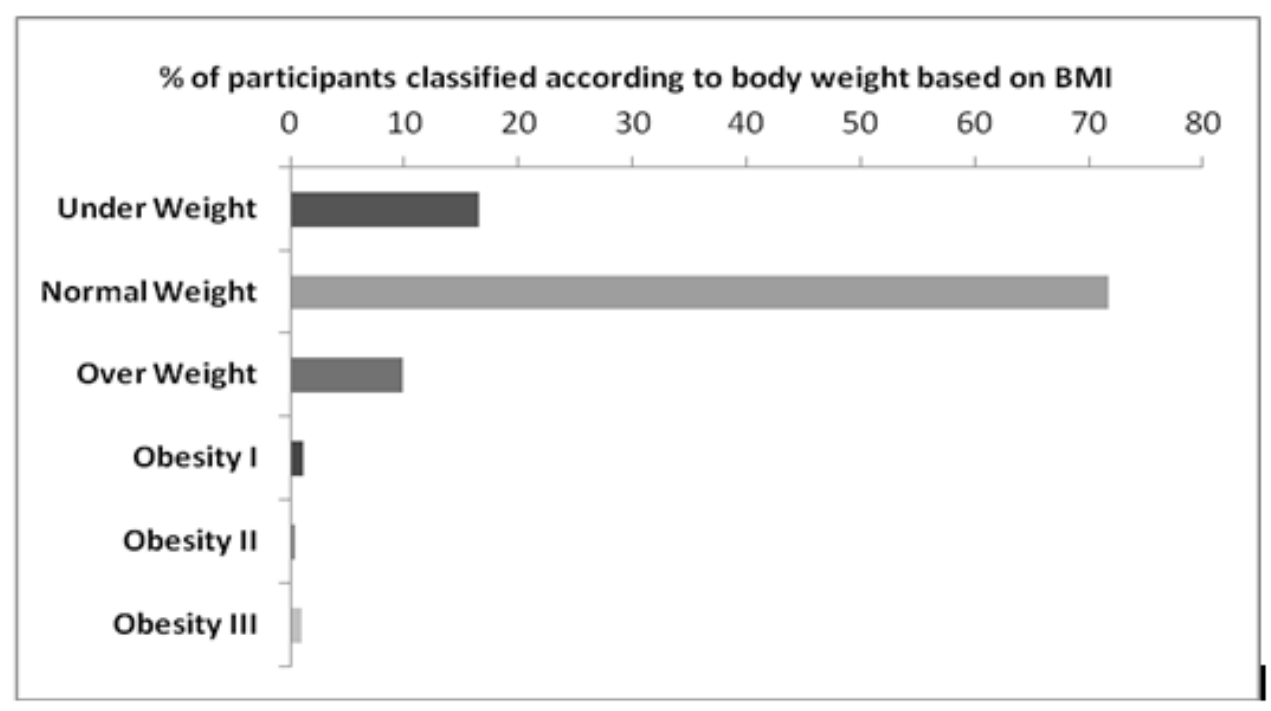

Fig. 1: BMI of participants involved in the study according to body weight

\section{Life style}

With regards to eating habits, the results showed that half of the respondents $50.7 \%(n=1259)$ consumed 3 meals per day.
Participants who reported consuming chicken in the majority of meals, about $16.7 \% \quad(n=414)$, showed higher menstrual irregularity $(\mathrm{P} \leq 0.001)$ than those $33.3 \%$ who did not $(\mathrm{n}=827)$ (fig. 2). 


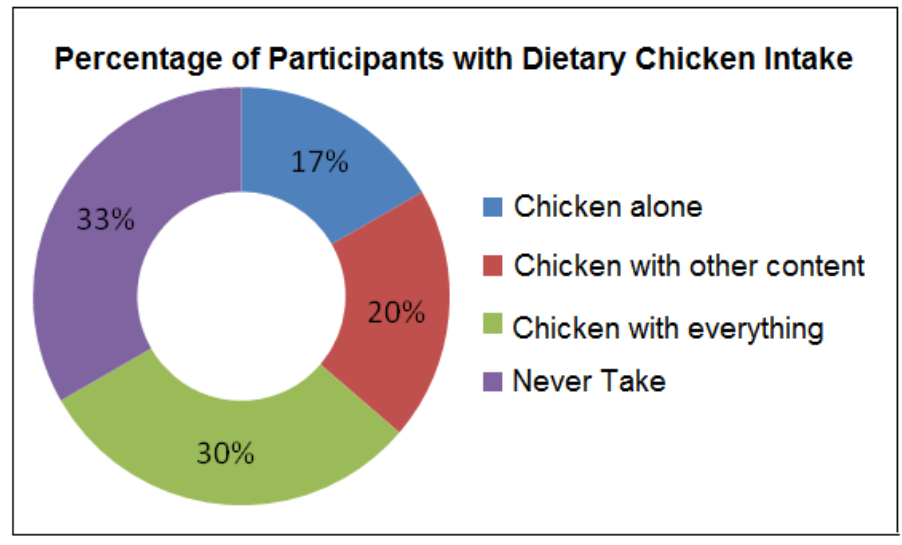

Fig. 2: The distribution of participant involved in the study according to dietary intake

Regarding sleeping hours, among $40 \%(n=991)$ of participants who reported less than $6 \mathrm{~h}$ of sleep, showed higher stress $(P \leq 0.001)$, suffered more bleeding irregularity $(P \leq 0.001)$ than those with $6 \mathrm{~h}$ or more of sleep. In response to lifestyle pattern questions, the majority of participants $75 \%(n=1862)$ revealed that they consumed fast food and similar results $72.8 \%(n=1806)$ were obtained from the women whom included fruit and vegetables in their diet. Other lifestyle patterns are included in the table below (table 2).

Table 2: Life style pattern among participants

\begin{tabular}{|c|c|c|}
\hline Parameter & Number of participants & Percent \\
\hline \multicolumn{3}{|c|}{ Fast food Intake } \\
\hline No & 619 & 25 \\
\hline Yes & 1862 & 75 \\
\hline \multicolumn{3}{|c|}{ Fruits and vegetables Intake } \\
\hline No & 675 & 27.2 \\
\hline Yes & 1806 & 72.8 \\
\hline \multicolumn{3}{|c|}{ Tea and coffee Intake } \\
\hline No & 906 & 36.6 \\
\hline Yes & 1575 & 63.5 \\
\hline \multicolumn{3}{|c|}{ Energy drinks Intake } \\
\hline No & 2141 & 86.3 \\
\hline Yes & 340 & 13.7 \\
\hline \multicolumn{3}{|l|}{ Smoking } \\
\hline No & 2177 & 87.7 \\
\hline Yes & 304 & 12.3 \\
\hline \multicolumn{3}{|l|}{ Sports } \\
\hline No & 1197 & 48.2 \\
\hline Yes & 1283 & 51.7 \\
\hline \multicolumn{3}{|l|}{ Heavy sports } \\
\hline No & 2425 & 97.7 \\
\hline Yes & 55 & 4.9 \\
\hline \multicolumn{3}{|c|}{ Use of herbal remedies during PMS } \\
\hline No & 950 & 38.3 \\
\hline Yes & 1531 & 61.7 \\
\hline
\end{tabular}

Table 3: Level of stress among young females

\begin{tabular}{lll}
\hline Stress level & Number of participants & Percentage (\%) \\
\hline Mild & 504 & 20.3 \\
moderate & 1818 & 73.3 \\
severe & 159 & 6.4 \\
\hline
\end{tabular}

\section{Stress}

The reported perceived stress showed that, the majority of participants $73.3 \%(\mathrm{n}=1818)$ expressed moderate stress (table 3). Females who expressed higher stress had sleeping hours less than $6 \mathrm{~h}$ $(P \leq 0.001)$ and even suffered more with menstrual irregularity $(P \leq$ $0.001)$.

\section{Knowledge}

The total survey revealed that $81.9 \%(\mathrm{n}=2032)$ of participants had good knowledge about their menstrual health, while $18.09 \%$ $(\mathrm{n}=449)$ reported to have less knowledge. The participants over 18 y's old age showed greater knowledge than those of younger age. The participants who indicated good knowledge about their menstrual pathology and menstrual hygiene expressed less stress levels $(\mathrm{P} \leq 0.001)$ than those with nil or lower knowledge. The data analyzed indicated key responses. The average menarche age was observed as $12.58 \pm 1.432(11.148-14.012)$ years; about $32.1 \%$ $(n=796)$ of participants had their menses at the age of 13 . In addition, $5.2 \%(\mathrm{n}=130)$ of the surveyed girls had early menarche $\leqslant$ 11.148 y) which showed a significant irregularity ( $\leq \leq 0.001) .2 .8 \%$ $(n=69)$ of participants from the total study size, had a menses 
period $<21 \mathrm{~d}, 16.3 \%(\mathrm{n}=406)$ of them had menses $>35 \mathrm{~d}$ and $80.9 \%$ $(\mathrm{n}=2006)$ between 21 to $35 \mathrm{~d}$ (table 4). $25 \%(\mathrm{n}=621)$ of the surveyed young females were having irregular menstrual cycles and the other $75 \%(n=1860)$ were having regular menses.

\section{Pain and analgesic use}

About half of the population $50.9 \%(n=1262)$ of the surveyed participants reported severe pain that was managed by using analgesics. The majority of respondents, $61.7 \%(n=1531)$ preferred herbal remedies than analgesic drugs during their PMS. $51.3 \%$ $(n=1273)$ of participants reported the usage of analgesics during their PMS, and $48.7 \%(n=1208)$ did not use any drugs to counter the pain. About analgesic used, only $8.1 \%(n=201)$ analgesic drugs were taken according to medical advice. Replies of participants who used the analgesic drugs showed that $3.8 \%(n=49)$ of them were using analgesics appropriately (before the expected day of the monthly period) while $96.2 \%$ of them $(n=1224)$ were using analgesic inappropriately.

Table 4: Menstrual patterns of among the participants

\begin{tabular}{lll}
\hline Variable & Number of participants & \% \\
\hline Duration of the menstrual cycle & & \\
Shorter than 21 d & 69 & 2.8 \\
$21-35$ d & 2006 & 80.9 \\
Longer than 35 d & 406 & 16.3 \\
Pain & & 8.5 \\
Severe, Can't be handled even with analgesic & 211 & 34.1 \\
Normal & 847 & 50.9 \\
Severe Can be handled with analgesic & 1262 & 6.5 \\
No pain & 161 & \\
\hline
\end{tabular}

\section{DISCUSSION}

Most of the invited participants, about $98.24 \%$, took part in this survey and showed a favorable response. The positive response may be due to interest in and importance of the study and by the simplicity of the survey's questionnaire [20,21]. About $90.7 \%$ of the respondents were Saudi young female; while $9.3 \%$ were non-Saudi which resemble the exact percentage of non-Saudi students in the Saudi schools. In this study, the participants' average age was $19.83 \pm 3.053$ y. $71.6 \%$ of them had normal weight and only $9.7 \%$ and $2.2 \%$ were overweight and obese, respectively. In contrast, findings from a recent Saudi study showed that $3.2 \%$ of the Saudi females were obese and $31.8 \%$ were overweight. This difference may be due to this study sample being younger and more concerned about their weight and shape [22]. The survey results revealed that there is a close association between low BMI and menstrual irregularity which was the same as result found in Spanish study that indicated females who are trying to reduce the bodyweight have shown a higher incidence of menses pain and irregularity [23]. On the other hand, a study conducted among Taiwanese college nursing students proved that women with obesity exhibited both higher risk long menses along with irregularity as well [24]. Therefore, correlating both weight and BMI may become a topic in investigating menstrual irregularity.

The study provided a deeper understanding of the effect of chicken intake on the menstrual irregularities. The survey indicated that women whom had higher consumption of chicken exhibited more menstrual irregularities than others [25]. This may be due to the fact that chicken contains high amount of estrogen hormones [26]. An individual's health is determined on the type of lifestyle adapted. Sedentary lifestyles always impact on menstrual irregularities. A healthy lifestyle with both physiological and psychological wellbeing can avoid stress and irregular menses. The study revealed a statistical significance that stress affects menstrual health; it was obvious that good modification of lifestyle pattern is important [27, 28]. As Thomas F et al. showed, "Menarche age varies globally and is likely to be affected in developing countries like Haiti, where the average menarche is at 15.3 y [29]. Studies even reported that menarche age varies with civilization, for example, Ethiopian females; from urban areas have a higher incidence of menstrual problems in comparison to rural areas [30]. Both of the reports were in agreement with similar findings in Nigeria and Morocco $[31,32]$. The results of our study indicated that females in Saudi Arabia exhibited a mean menarche age of $12.85 \pm 1.432$ which is in agreement with previous findings of menses being influenced by socioeconomic and nutritional conditions [33].

From the total study population, about $25 \%$ participants exhibited irregular duration of menses ( $>35 \mathrm{~d}$ ) which usually might be due to ovulation or tumors or stress or smoking or alcohol consumption.
The influence of these factors over the menses needs to be explored and is important for further research [34]. Also, our survey outcomes showed that early menarche is associated with menstrual irregularity [35]. The effect and prevalence of dysmenorrhea (pain during menstruation) was even reported as $59.4 \%(n=1473)$ of the participants in our study. A similar result $(67.7 \%)$ was found among Malaysian school girls [36]. The result of this study showed only $23.3 \%$ of participants younger than $18 \mathrm{y}$ knew about their menstrual health from sources other than health care professionals and in another study, only $2 \%$ of its study respondents were able to provide or share menses information from doctors [37]. Since knowledge about menstruation from qualified sources (health care professionals) is an important factor for solving arising issues in younger females, improvements in health care guidance in regard to menstrual disorders should be made.

This study showed that analgesics were used inappropriately among $96.2 \%$, participants, on the other hand only $2 \%$ of them were advised by physicians or pharmacists to take analgesics appropriately (before expected day of monthly period). These obtained results were different in comparison to other studies that $85 \%$ took analgesics to counter pain during PMS [38]. These findings indicate that health care professionals such as doctors, pharmacists and nurses should give more information in regard patient's education about the use of OTC analgesics and this may prompt the identification and diagnosis of disorders relating to menses thereby reducing the misusage of drugs. Menstrual irregularities among young women differ from one society to another due to their socioeconomic status and other characteristic problems associated with individual societies [39]. Overall, the survey indicated that the actual causes for menstrual irregularities among Saudi females appear to be influenced by stress and sedentary lifestyle.

\section{CONCLUSION}

Dysmenorrhea is a common health issue for young females. Low BMI, sedentary lifestyle pattern, stress and early age of menarche are the most important factors associated with menstrual irregularities. Lack of counselling and improper awareness about menstrual health can become a major issue at a young age, this issue can be resolved by good initiatives such as proper education about menstrual health and to mitigate cost effective diagnosis for patients with dysmenorrhea. On the other hand there is a need for health care professionals such as doctors or pharmacists to communicate the benefits of analgesics prescribing during PMS.

\section{ACKNOWLEDGMENT}

We would like to thank all the participants in this study. Special thanks go to the expert panel for their valuable input during the period of the study tool validation. 


\section{FUNDING}

Nil

\section{AUTHORS CONTRIBUTIONS}

All authors have contributed to the questioner design, data collection and analysis and to the writing of the manuscript.

\section{CONFLICT OF INTERESTS}

The author declares no conflict of interest.

\section{REFERENCES}

1. Burrows A, Johnson S. Girls' experiences of menarche and menstruation. J Reprod Infant Psychol 2005;23:235-49.

2. Chang YT, Chen YC, Hayter M, Lin ML. Menstrual and menarche experience among pubescent female students in taiwan: implications for health education and promotion practice. J Clin Nurs 2009;18:2040-8.

3. Thomas F, Renaud F, Benefice E, De Meeüs T, Guegan JF. International variability of ages at menarche and menopause: patterns and main determinants. Huma Biol 2001;73:271-90.

4. Kaplowitz P. Pubertal development in girls: secular trends. Curr Opin Obstet Gynecol 2006;18:487-91.

5. Bean JA, Leeper JD, Wallace RB, Sherman BM, Jagger $H$. Variations in the reporting of menstrual histories. Am J Epidemiol 1979;109:181-5.

6. Rebuffe Scrive M, Enk L, Crona N, Lonnroth P, Abrahamsson L, Smith U, et al. Fat cell metabolism in different regions in women. Effect of the menstrual cycle, pregnancy, and lactation. J Clin Investig 1985;75:1973-6.

7. Harlow SD, Campbell OM. Epidemiology of menstrual disorders in developing countries: a systematic review. BJOG: An Int J Obstet Gynecol 2004;111:6-16.

8. Harel Z. Dysmenorrhea in adolescents and young adults: etiology and management. J Pediatr Adolesc Gynecol 2006;19:363-71.

9. Kettaneh APS, Todesco M. Good policy and practice booklet no. 9: puberty education and menstrual hygiene management. Paris: United Nations Educational, Scientific and Cultural Organization; 2014.

10. Always. Tips and advice: "the talk". Available from: http://always.com/en-us/tips-and-advice/the-talk. [Last accessed on 15 Oct 2014]

11. Pettersson F, Fries H, Nillius SJ. Epidemiology of secondary amenorrhea: I. Incidence and prevalence rates. Am J Obstet Gynecol 1973;117:80-6.

12. Baker ER, Mathur RS, Kirk RF, Williamson HO. Female runners and secondary amenorrhea: correlation with age, parity, mileage, and plasma hormonal and sex-hormone-binding globulin concentrations. Fertil Steril 198;36:183-7.

13. Fries H, Nillius SJ, Pettersson F. Epidemiology of secondary amenorrhea: II. A retrospective evaluation of etiology with special regard to psychogenic factors and weight loss. Am J Obstet Gynecol 1974;118:473-9.

14. Drew FL. The epidemiology of secondary amenorrhea. J Clin Epidemiol 1961;14:396-407.

15. Loucks AB, Horvath SM. Athletic amenorrhea: a review. Med Sci Sport Exerc 1985;17:56-72.

16. American Academy of Pediatrics, American College of Obstetricians and Gynecologists. Menstruation in girls and adolescents: using the menstrual cycle as a vital sign. Pediatr 2006;118:2245-50.
17. Cohen S, Kamarck T, Mermelstein R. A global measure of perceived stress. J Health Soc Behav 1983;24:385-96.

18. Campbell MA, McGrath PJ. Use of medication by adolescents for the management of menstrual discomfort. Arch Pediatr Adolesc Med 1997;151:905-13.

19. Boscolo P, Mason L. Topic knowledge, text coherence, and interest: How they interact in learning from instructional texts. J Exp Educ 2003;71:126-48.

20. Moos RH. The development of a menstrual distress questionnaire. Psychosom Med 1968;30:853-67.

21. Groves RM, Presser S, Dipko S. The role of topic interest in survey participation decisions. Public Opin Q 2004;68:2-31.

22. Al-Nozha MM, Al-Mazrou YY, Al-Maatouq MA, Arafah MR, Khalil MZ, Khan NB, et al. Obesity in Saudi Arabia. Saudi Med J 2005;26:824-9.

23. Montero P, Bernis C, Fernandez V, Castro S. Influence of body mass index and slimming habits on menstrual pain and cycle irregularity. J Biosoc Sci 1996;28:315-23.

24. Chang PJ, Chen PC, Hsieh CJ, Chiu LT. Risk factors on the menstrual cycle of healthy taiwanese college nursing students. Aust N Z J Obstet Gynaecol 2009;49:689-94.

25. Cross GB, Marley J, Miles H, Willson K. Changes in nutrient intake during the menstrual cycle of overweight women with premenstrual syndrome. Br J Nutr 2001;85:475-82.

26. Poppitt SD, McCormack D, Buffenstein R. Short-term effects of macronutrient preloads on appetite and energy intake in lean women. Physiol Behav 1998;64:279-85.

27. Fenster L, Waller K, Chen J, Hubbard AE, Windham GC, Elkin E, et al. Psychological stress in the workplace and menstrual function. Am J Epidemiol 1999;149:127-34.

28. Yamamoto K, Okazaki A, Sakamoto Y, Funatsu M. The relationship between premenstrual symptoms, menstrual pain, irregular menstrual cycles, and psychosocial stress among Japanese college students. J Physiol Anthropol 2009;28:129-36.

29. Barnes Josiah D, Augustin A. Secular trend in the age at menarche in Haiti. Am J Hum Biol 1995;7:357-62.

30. Zegeye DT, Megabiaw B, Mulu A. Age at menarche and the menstrual pattern of secondary school adolescents in northwest Ethiopia. BMC Women's Health 2009;9:29.

31. Thomas KD, Okonofua FE, Chiboka O. A study of the menstrual patterns of adolescents in Ile-Ife, Nigeria. Obstet Gynecol Int ] 1990;33:31-4.

32. Loukid M, Baali A, Hilali MK. Secular trend in age at menarche in Marrakesh (Morocco). Ann Hum Biol 1996;23:333-5.

33. Babay Z. Age at menarche and the reproductive performance of Saudi women. Age 2004;15:14

34. Pomerleau CS, Cole PA, Lumley MA, Marks JL, Pomerleau OF. Effects of menstrual phase on nicotine, alcohol, and caffeine intake in smokers. J Subst Abus 1994;6:227-34.

35. Cakir M, Mungan I, Karakas T, Girisken I, Okten A. Menstrual pattern and common menstrual disorders among university students in turkey. Pediatr Int 2007;49:938-42.

36. Wong LP, Khoo EM. Dysmenorrhea in a multiethnic population of adolescent Asian girls. Int J Obstet Gynecol 2010;108:139-42.

37. Houston AM, Abraham A, Huang Z, D'Angelo LJ. Knowledge, attitudes, and consequences of menstrual health in urban adolescent females. J Pediatr Adolesc Gynecol 2006;19:271-5.

38. Campbell EM, Peterkin D, O'grady K, Sanson Fisher R Premenstrual symptoms in general practice patients. Prevalence and treatment. J Reprod Health Med 1997;42:637-46.

39. Dars S, Sayed K, Yousufzai Z. Relationship of menstrual irregularities to BMI and nutritional status in adolescent girls. Pak J Med Sci 2014;30:141. 